\title{
Ulam's type stabilities for conformable fractional differential equations with delay
}

\author{
Sen Wang ${ }^{1}$, Wei Jiang ${ }^{1}$, Jiale Sheng ${ }^{1}$, and Rui Li $^{1}$ \\ ${ }^{1}$ Anhui University
}

November 5, 2020

\begin{abstract}
In this paper, we investigate the existence and uniqueness of solutions and Ulam's type stabilities including the well-known UlamHyers stability and the newly extended Ulam-Hyers' conformable exponential stability for two classes of fractional differential equations with the conformable fractional derivative and the time delay. The Banach contraction principle, the technique of Picard operator, the Gronwall integral inequalities and generalized iterated integral inequality in the sense of conformable fractional integral are the main tools for deriving our main results. Finally, several illustrative examples will be presented to demonstrate our work.
\end{abstract}

\section{Hosted file}

MMA.pdf available at https://authorea.com/users/373405/articles/491110-ulam-s-typestabilities-for-conformable-fractional-differential-equations-with-delay

\section{Hosted file}

MMA.tex available at https://authorea.com/users/373405/articles/491110-ulam-s-typestabilities-for-conformable-fractional-differential-equations-with-delay 